\title{
MEMBANGUN APLIKASI PERBAIKAN KENDARAAN OPERASIONAL PADA KELURAHAN MUNJUL
}

\author{
Novi Astianie ${ }^{1}$, Thomas Afrizal ${ }^{2}$, Rosdiana $^{3}$ \\ 1,2,3 Jurusan Teknik Informatika,Fakultas Ilmu Komputer, Universitas Indraprasta PGRI Jakarta \\ Jalan Raya Tengah No 80, Kelurahan Gedong, Pasar Rebo, Jakarta Timur \\ 1astianienovi@gmail.com, 르omztaurus.it@gmail.com, ${ }^{3}$ rosdianasidik.rs@gmail.com
}

\begin{abstract}
ABSTRAK
Kelurahan Munjul adalah instansi pemerintahan yang dimana masih memiliki banyak permasalahan. Pengolahan data-data perbaikan kendaraan operasional masih menggunakan proses manual dengan menuliskan nya didalam buku besar dan data perbaikan kendaraan operasional ini dengan cara mengecek satu persatu data kendaraan operasional sehingga pengecekan tidak efisien. Tujuan merancang suatu sistem aplikasi perbaikan kendaraan operasional ini yaitu untuk memudahkan admin dalam memproses pengolahan data yang ada saat ini hingga sampai ke pelaporannya. Perangkat aplikasi yang telah dibuat dengan bahasa pemrograman Java NetBeans 8.0.2 dan penyimpanan data pada database MySQL dapat memberikan kelancaran dalam proses menginput dan penyimpanan data-data serta laporan-laporan yang diberikan kepada pimpinan perusahaan. Metode pengembangan sistem yang digunakan yaitu Waterfall dengan tahapan-tahapan seperti rekayasa sistem, analisis, desain, coding, testing, dan maintenance. Hasil dari penelitian ini menciptakan suatu sistem aplikasi perbaikan kendaraan operasional yang dapat membantu proses menganalisa dan memonitoring kendaraan operasional yang tersaji dalam bentuk aplikasi program berbasis desktop sehingga prosesnya menjadi lebih baik dan efisien.
\end{abstract}

Kata Kunci: Aplikasi, Perbaikan, Kendaraan, Operasional, Desktop

\section{ABSTRACT}

Munjul Village is a government agency which still has many problems. Processing of operational vehicle repair data still uses a manual process by writing it down in the ledger and this operational vehicle repair data by checking operational vehicle data one by one so that checking is not efficient. The purpose of designing an operational vehicle repair application system is to make it easier for admins to process the current data processing up to reporting. Application tools that have been created using the Java NetBeans 8.0.2 programming language and data storage in the MYSQL database can provide smooth processing of input and storage of data and reports provided to company leaders. The system development method used is Waterfall with stages such as systems engineering, analysis, design, coding, testing, and maintenance. The results of this study create an operational vehicle repair application system that can help the process of analyzing and monitoring operational vehicles which is presented in the form of a desktop-based program application so that the process becomes better and more efficient.

Key Word: Application, Repair, Vehicle, Operational, Desktop

\section{PENDAHULUAN}

Teknologi diharapkan dapat menjadi fasilitator dan interpreter. Semula teknologi informasi digunakan hanya sebatas pada pemrosesan data (Mulyadi, 2016). Teknologi informasi adalah suatu teknologi yang digunakan untuk mengolah data, termasuk memproses, mendapatkan, menyusun, menyimpan, memanipulasi data dalam berbagai cara untuk menghasilkan informasi yang berkualitas, yaitu informasi yang relevan, akurat dan tepat waktu, yang digunakan keperluan pribadi, bisnis, dan pemerintahan dan merupakan informasi yang strategis untuk pengambilan keputusan (Sutabri, 2012).

Sistem informasi yang mendukung membuat kinerja perusahaan akan terlaksana dengan baik dan dibuat untuk mempermudah dalam pengelolaan dan penyimpanan data maka dapat menghasilkan suatu informasi yang tepat dengan menggunakan perangkat lunak dan perangkat keras yang sesuai dengan kebutuhan pengguna (Triwahyuni, 2013). Adanya sistem informasi 
dapat mengurangi terjadinya kesalahan yang tidak diinginkan sehingga dapat meningkatkan kinerja yang lebih efisien dan kecepatan operasional perusahaan.

Secara teknis pemeliharaan kendaraaan terdiri dari perawatan dan service (Kurniawan \& Awalludin, 2020). Perawatan kendaraan secara umum antara lain ganti oli, tune up, ganti freon $A C$, fanbelt, timing belt yang dilakukan secara berkala. Sedangkan service merupakan proses perbaikan kendaraan yang dilakukan dengan pergantian spare part maupun tidak. Secara administrasi pemeliharaan kendaraan ini perlu dilakukan pencatatan, hal tersebut dimaksudkan agar kendaraaan selalu termonitor kondisi dan jadwal perawatan berkala (Kumala \& Winardi, 2020).

Munjul adalah salah satu kelurahan di kecamatan Cipayung Jakarta Timur, DKI Jakarta. Kelurahan Munjul memiliki kodepos 13850. Kelurahan Munjul merasa perlu untuk menggunakan sistem informasi perbaikan kendaraan operasional agar penanganan kendaraan yang berjumlah lebih dari 50 kendaraan pimpinan dan staff dapat berlangsung dengan baik. Dengan mengandalkan sistem informasi maka proses penanganan, mulai dari pelaporan hingga perbaikan dapat segera tertangani, demikian juga sistem ini akan sangat mendukung pengambilan keputusan yang berkaitan dengan perbaikan kendaraan (Fauzan et al., 2018).

Dari sebuah permasalahan tersebut maka dilakukan penelitian yang ada pada Kelurahan Munjul, dimana dalam pembutan laporan perbaikan kendaraan operasional masih kurang efektif dikarenakan pengelolaan data kendaraan dan beberapa data-data pendukung masih di kelola secara manual. sehingga proses pengerjaannya berjalan lambat dan penyajian laporan pun akan terlambat pula, sehingga proses perbaikan kendaraan operasional yang diperlukan akan ikut terlambat dan ini mempengaruhi kinerja pegawai Kelurahan Munjul.

Dengan permasalahan tersebut, perlu ada nya suatu sistem yang terkomputerisasi dalam penyelesaiannya. Sistem adalah sekelompok unsur yang erat hubungannya satu dengan yang lain, yang berfungsi bersama-sama untuk mencapai tujuan (Sutabri, 2012). Sistem merupakan suatu kumpulan dari komponenkomponen yang membentuk satu kesatuan (Tyoso, 2016). Pembangunan sistem adalah sekumpulan aktivitas yang menggambarkan secara rinci bagaimana sistem akan berjalan. Hal itu bertujuan untuk menghasilkan produk perangkat lunak yang sesuai dengan kebutuhan user (Satzinger, J. W., Jackson, R. B., Burd, n.d.).

Diharapkan dengan adanya suatu sistem informasi dapat menangani permasalahan yang ada di perusahaan tersebut. Sistem adalah setiap sesuatu terdiri dari obyek-obyek, atau unsurunsur, atau komponen-komponen yang bertata kaitan dan bertata hubungan satu sama lain, sedemikian rupa sehingga unsur-unsur tersebut merupakan satu kesatuan pemrosesan atau pengolahan yang tertentu. (Prasojo, 2011)

Aplikasi ini dapat memudahkan pekerjaan Admin dalam melaksanakan pembuatan laporan dan dapat memudahkan pihak perusahaan dalam memproses data perbaikan kendaraa operasional pada Kelurahan Munjul.

\section{METODE PENELITIAN}

Peneliti menggunakan metode Research and Development dalam penyelesaian penelitian ini. (Sugiyono, 2016). Dalam pelaksanaan R\&D, ada beberapa metode yang digunakan yaitu metode deskriptif, evaluatif dan eksperimental. Metode penelitian deskriptif digunakan dalam penelitian awal untuk menghimpun data tentang kondisi yang ada yaitu penulis membutuhkan data-data yang dapat menunjang tercipta nya suatu sistem informasi perbaikan kendaraan operasional seperti data kendaraan, data petugas, data bengkel, data perbaikan kendaraan operasional dan data pemeliharaan kendaraan operasional terdahulu yang masih tersimpan secara manual didalam buku besar. Metode evaluatif digunakan untuk mengevaluasi proses ujicoba pengembangan suatu produk, dalam proses ini penulis melakukan ujicoba terhadap suatu sistem yang telah dirancang agar tidak ada terjadi kesalahan dalam proses penginputan data serta pelaporan bulanan kepada pimpinan. Dan metode eksperimen digunakan untuk menguji 
keampuhan dari produk yang dihasilkan, dalam proses yang terakhir ini perlu dilakukan pengujian akhir yang diharapkan bahwa sistem yang dirancang oleh penulis dapat berjalan dengan baik dan sesuai dengan kebutuhan dan terfokus pada proses perbaikan kendaraan operasional pada Kelurahan Munjul. (Putra, 2011).

Adapun lokasi penelitian dilakukan di Kelurahan Munjul selam 3 bulan, berikut jadwal penelitiannya:

Pada bulan ke-1 dilakukan proses analisis kebutuhan sistem, mendapatkan data-data yang dibutuhkan untuk perancangan sistem. Kemudian bulan ke-2 dilakukan proses observasi, mempelajari proses-proses pada Kelurahan Munjul dengan memahami proses pendataan kendaraan, pendataan data bengkel dan pendataan data perbaikan kendaraan serta pembuatan laporan. Bulan ke-3 dilakukan proses implementasi sistem dan pengujian sistem tersebut, sistem aplikasi yang sesuai dengan kebutuhan perusahaan sehingga dapat menghasilkan kinerja perusahaan menjadi lebih baik dan efektif.

\section{HASIL DAN PEMBAHASAN Analisa Permasalahan}

Dari hasil yang penulis lakukan maka penulis dapat menganalisis permasalahan yang ada pada Kelurahan Munjul, yaitu:

1. Sistem yang selama ini di pakai tidak efisien untuk pembuatan laporan dan kurang terjaga keamanannya. Jika admin ingin membuat laporan, maka arsip yang ada harus dikumpulkan dan dicatat satu persatu, tentu saja hal ini membuat bagian admin harus meluangkan waktu lebih banyak untuk pekerjaan ini.

2. Kurangnya sumber daya manusia yang memahami sistem komputerisasi menjadi suatu penyebab belum dibuatnya sistem aplikasi perbaikan kendaraan operasional di Kelurahan Munjul yang berbasis komputerisasi.

\section{Alternatif Penyelesaian Masalah}

Alternatif pemecahan masalah yang akan penulis lakukan untuk mempermudah proses kerja pada Kelurahan Munjul, yaitu:
1. Merancang sistem aplikasi yang lebih baik untuk dapat membantu kinerja bagian admin dalam mengelola setiap proses yang terjadi pada perusahaan serta membantu dalam mengolah data-data perusahaan.

2. Merancang sistem informasi perbaikan kendaraan operasional dengan sistem terkomputerisasi. Jadi, setiap proses perbaikan kendaraan operasional yang diajukan bagian operasional, seperti proses perbaikan kendaraan operasional dan proses persetujuan, dan data laporan akan disimpan ke dalam database. Kemudian laporan yang dibutuhkan akan ditampilkan secara otomatis tanpa harus menggunakan cara manual lagi.

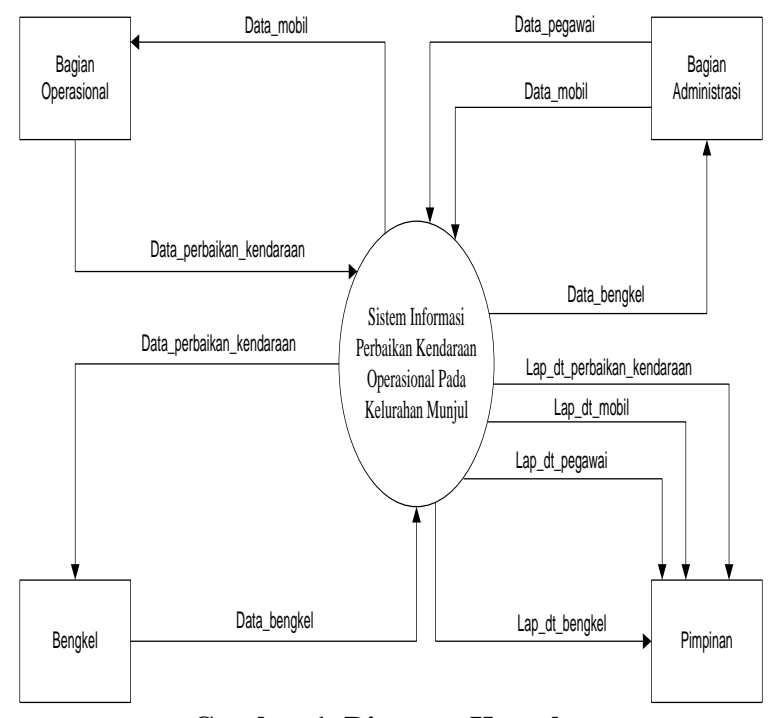

Gambar 1. Diagram Konteks

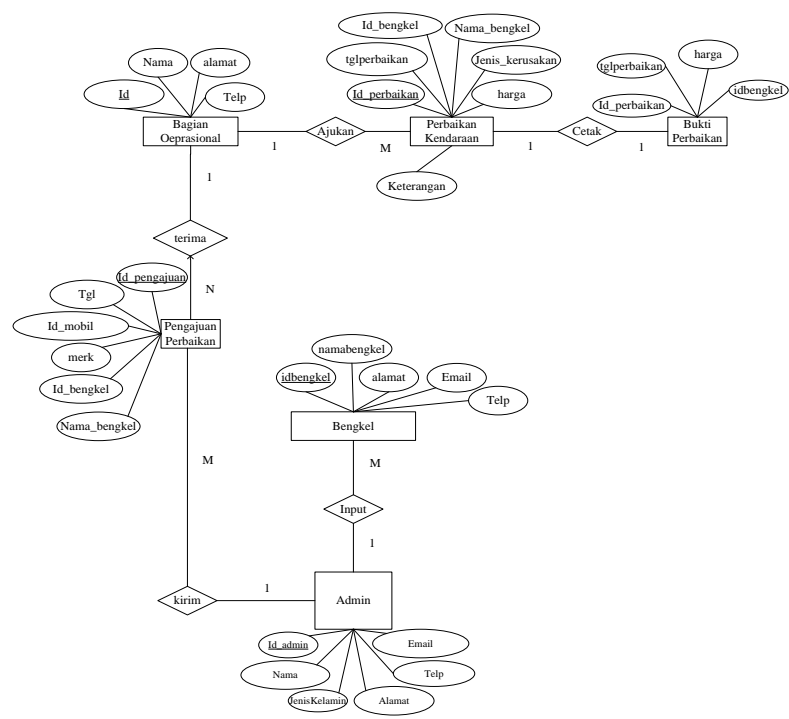

Gambar 2. ERD (Entity Relationship Diagram) 
Berikut adalah tampilan layar dan hasil pengujian pada software program yang telah di buat dengan bahasa pemrograman Java.

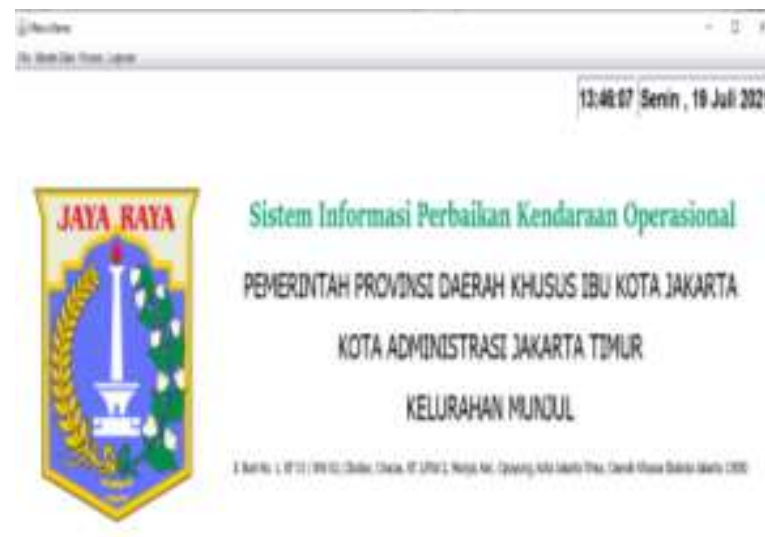

Gambar 3. Form Menu Utama

Layar di atas menampilkan tampilan Menu Utama pada Sistem Informasi Perbaikan Kendaraan pada Kelurahan Munjul. Pada layar utama tersedia menu bar yang terdiri dari master data yang digunakan untuk memasukkan data yang berkaitan dengan data pegawai, data kendaraan, data bengkel, data perbaikan kendaraan dan laporan-laporan.

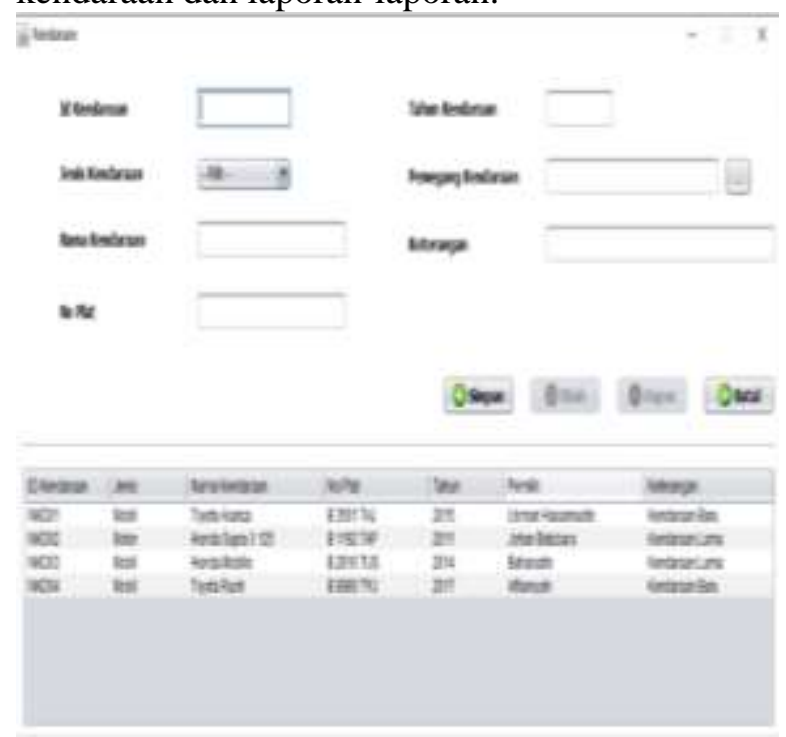

Gambar 4. Form Data Kendaraan

Layar di atas menampilkan tampilan form data kendaran. Pada layar form data kendaraan untuk meng-input data kendaraan yang terdiri dari Id Kendaraan, Jenis Kendaraan, Nama Kendaraan,
No Plat, Tahun Kendaraan, Pemegang Kendaraan, Keterangan.

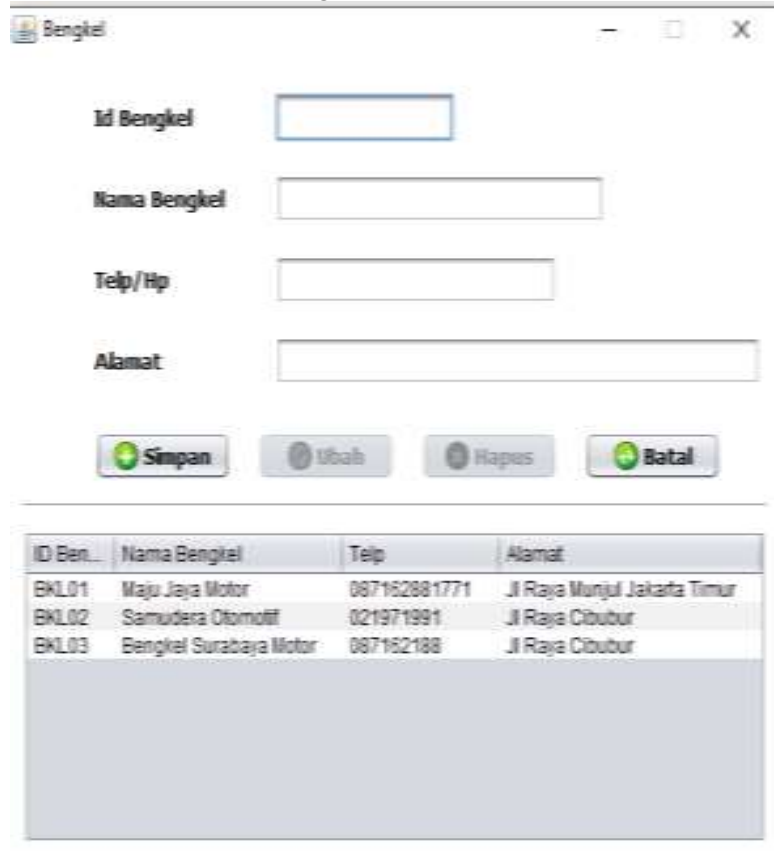

Gambar 5. Form Data Bengkel

Layar di atas menampilkan tampilan form data bengkel. Pada layar form data bengkel untuk meng-input data bengkel yang terdiri dari Id Bengkel, Nama Bengkel, Telp/HP dan Alamat.

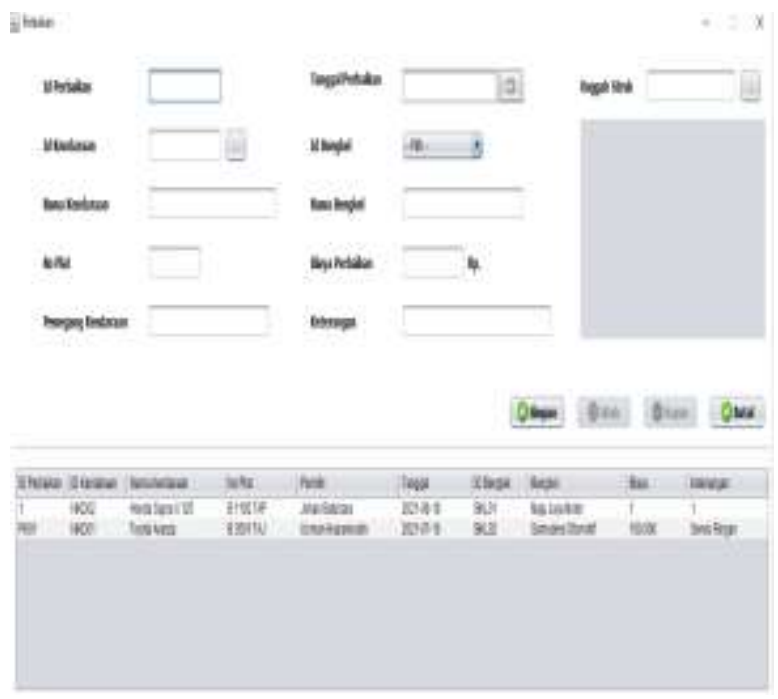

Gambar 6. Data Form Data Perbaikan Kendaraan

Layar di atas menampilkan tampilan form data perbaikan kendaraan. Pada layar form data perbaikan kendaraan untuk meng-input data perbaikan kendaraan yang terdiri dari Id Perbaikan, Id Kendaraan, Nama Kendaraan, No Plat, Pemegang Kendaraan, Tanggal Perbaikan, 
Id Bengkel, Nama Bengkel, Biaya Perbaikan, Keterangan dan Unggah Struk.

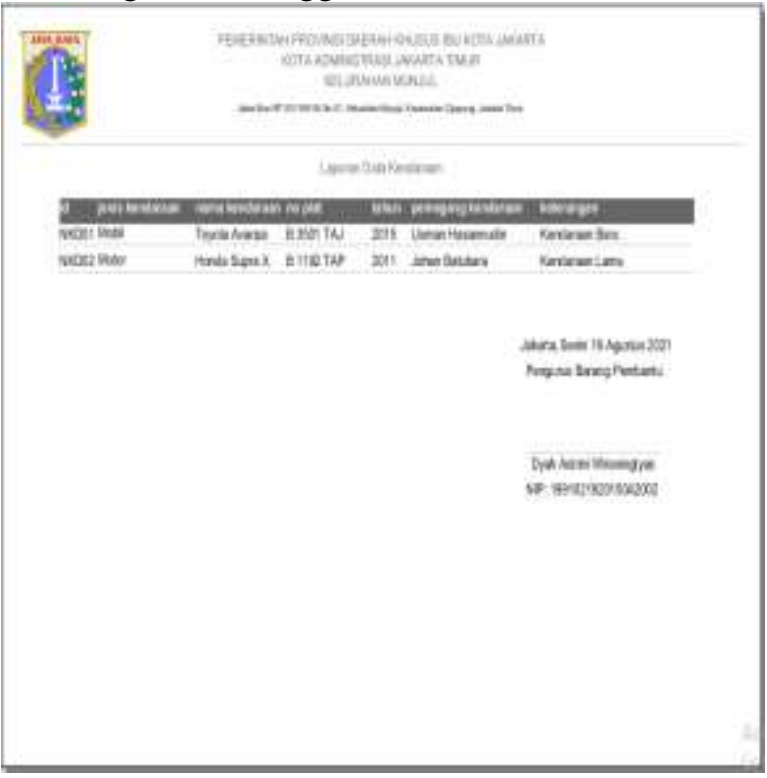

Gambar 7. Laporan Data Kendaraan

Layar di atas menampilkan tampilan form laporan data kendaraan. Pada layar form data kendaraan digunakan untuk mengecek laporan data kendaraan terdiri ID Kendaraan, Jenis Kendaraan, Nama Kendaraan, No Plat, Tahun, Pemegang Kendaraan, dan Keterangan.

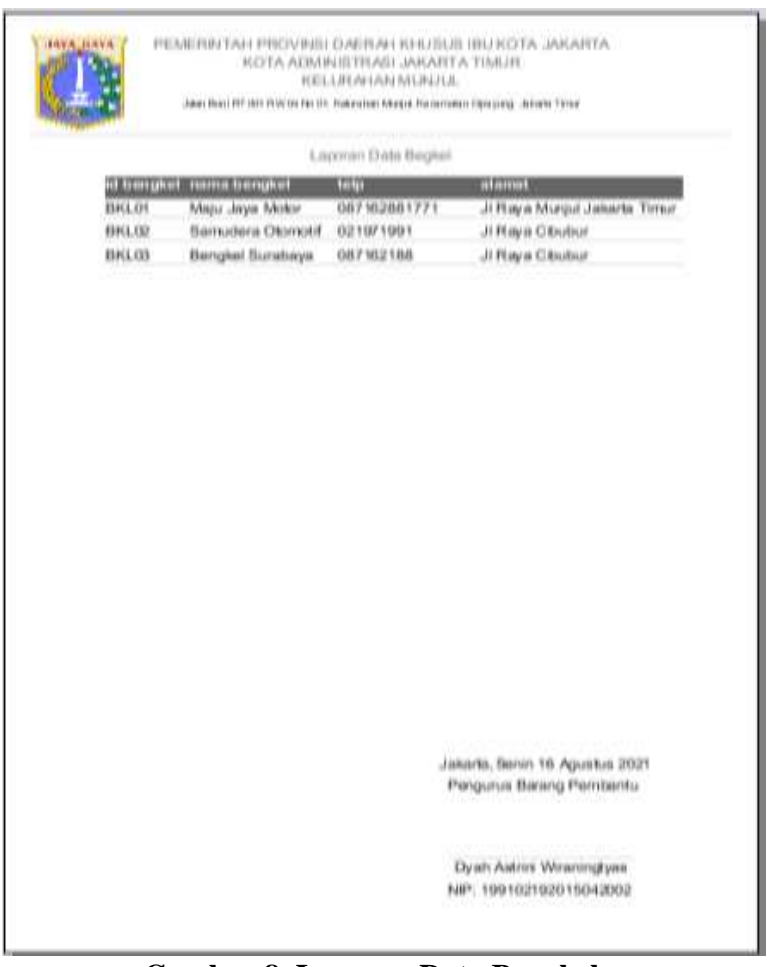

Gambar 8. Laporan Data Bengkel
Layar di atas menampilkan tampilan form laporan data bengkel pada layar form data bengkel digunakan untuk mengecek laporan data bengkel terdiri Id Bengkel, Nama Bengkel, Telp/HP dan Alamat.

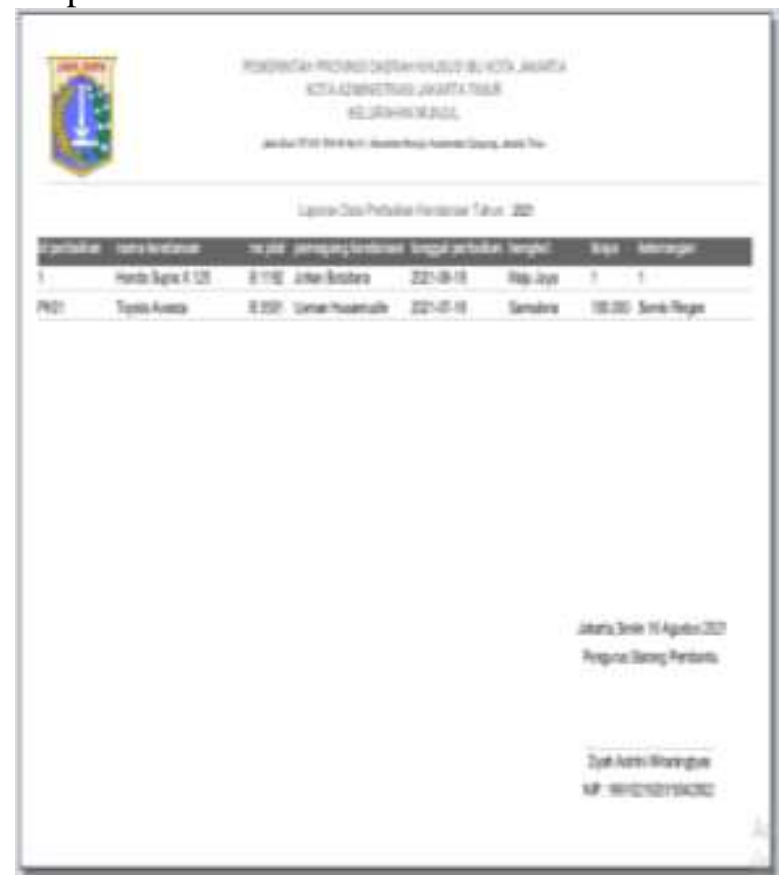

Gambar 9. Laporan Data Perbaikan Kendaraan

Layar di atas menampilkan tampilan form laporan data perbaikan kendaraan. Pada layar form data perbaikan kendaraan digunakan untuk mengecek laporan data perbaikan kendaraan terdiri Id Perbaikan, Nama Kendaraan, No Plat, Pemegang Kendaraan, Tanggal Perbaikan, Nama Bengkel, Biaya dan Keterangan.

\section{SIMPULAN DAN SARAN}

Dengan dibuatnya perancangan sistem informasi perbaikan kendaraan operasional di Kelurahan Munjul menggantikan sistem lama, admin tidak perlu melakukan penginputan data secara manual lagi, karena sistem aplikasi ini menyediakan form penginputan. Selain itu, sistem aplikasi tersebut juga sangat membantu admin dalam membuat laporan, karena sistem aplikasi dapat menghasilkan laporan harian maupun laporan bulanan yang dapat langsung dicetak.

Saran untuk penggunaan program ini perbaikan kendaraan operasional di Kelurahan Munjul dapat sangat terjaga keamanan datanya jika 
pimpinan perusahaan memilih orang yang tepat dan bertanggung jawab dalam menjalankan sistem tersebut.

Dan bagi peneli selanjutnya, hasil penelitian ini bisa digunakan sebagai bahan perbandingan dan referensi untuk penelitian, dan sebagai bahan pertimbangan untuk lebih memperdalam penelitian selanjutnya sehingga proses perbaikan kendaraan agar bisa lebih efektif dan real-time.

\section{DAFTAR PUSTAKA}

Fauzan, M. A., Putra, B. C., Informasi, S., Informasi, F. T., Luhur, U. B., Utara, P., \& Lama, K. (2018). Perawatan Kendaraan Dan Peralatan Pemadam Kebakaran Operasional Unit PKP-PK Pada PT. Angkasa Pura II. Jurnal Idealis, 1(1), 370374.

Kumala, A., \& Winardi, S. (2020). Aplikasi Pencatatan Perbaikan Kendaraan Bermotor Berbasis Android. Jurnal Intra Tech, 4(2), 112-120.

Kurniawan, A., \& Awalludin, D. (2020). Analisis Dan Perancangan Sistem Informasi Pengelolaan Kendaraan Operasional Berbasis Web Pada Pt Roda Pembina Nusantara. Jurnal Interkom: Jurnal Publikasi Ilmiah Bidang Teknologi Informasi Dan Komunikasi, 14(1), 16-23. https://doi.org/10.35969/interkom.v14i1.6 2

Mulyadi. (2016). Sistem Informasi Akuntansi. Jakarta: Salemba Empat.

Prasojo, M. (2011). Pengantar Sistem Informasi Manajemen. bandung: CV. Remadja Karya.

Putra, N. (2011). Research and Development, Penelitian dan Pengembangan: Suatu Pengantar. Jakarta: PT Raja Grafindo Persada.

Satzinger, J. W., Jackson, R. B., Burd, S. D. (n.d.). System Analysis and Design in A Changing World. USA: Cengage Learning.

Sugiyono. (2016). Metode Penelitian Kuantitatif, Kualitatif dan $R \& D$. Bandung: PT Alfabet.

Sutabri, T. (2012). Analisis Sistem Informasi. Yogyakarta: Andi.

Tata Sutabri. (2012). Analisis Sistem Informasi.
Yogyakarta: Andi Offset.

Triwahyuni, A. K. dan T. C. (2013). Pengantar Teknologi Informasi Edisi Revisi. Yogyakarta: Andi Offset.

Tyoso, J. S. P. (2016). Sistem Informasi Manajemen. Yogyakarta: DeePublish. 